\title{
Antiphospholipid syndrome and cancer
}

\author{
Razvan Adrian Ionescu
}

${ }^{1}$ 5th Department, Internal Medicine, "Carol Davila" University of Medicine and Pharmacy, Bucharest, Romania

2 3rd Clinic, Internal Medicine, Colentina Clinical Hospital, Bucharest, Romania

\section{INTRODUCTION}

Antiphospholipid syndrome (APS) is a systemic autoimmune disease, characterized by a pro thrombotic status which is due to the presence of antiphospholipid antibodies (aPL). Classically and part of the Sydney consensus on diagnostic criteria, these antibodies are anti cardiolipin (aCL) antibodies $\mathrm{IgG}$ or IgM, anti-beta-2-glicoprotein-I ( $\beta 2 \mathrm{GPI})$ antibodies IgG or IgM and lupus anticoagulant (LA). The first 2 are identified through enzyme-linked immunosorbent assays (ELISA), while the latter is identified through functional assay [1]. The clinical manifestations associated to APS pertain to vascular thrombosis and pregnancy morbidity. In order to make a correct diagnosis of APS, as per the Sidney criteria, one clinical and one laboratory criterion must be met [2]. It must be stressed out that the presence of apL alone does not establish the diagnosis of APS; a clinical manifestation attributable to the afore mentioned antibodies, must also be present.

Noteworthy, interestingly enough, low levels of aPL may also be found in otherwise normal people. Actually, in around $1-5 \%$ of healthy young persons, one can find aPL antibodies, with no known significance. This prevalence increases to $50 \%$ among elderly people that have a chronic disease [3]. Unfortunately, we do not know yet the importance and significance of these aPL antibodies in these people as we do not know what is the prevalence of APS in these groups of individuals. So, the presence of these kind of antibodies in these groups of people might be an epiphenomenon of some kind, or it might be the case that, in some particular circumstances, they "become" pathogenic and produce clinical manifestations in the form of APS. Nevertheless, the annual incidence of APS in the general positive for aPL population is 2.1 new cases per 100,000 persons and the estimated prevalence is 50 cases per 100,000 persons [4].

Some $1 \%$ of patients with APS, may present with a severe form of the disease, in which multiple organ failure is the main manifestation, known as catastrophic APS (CAPS) [5].

Antiphospholipid syndrome is classified, from an etiological point of view, as primary (when there is no evidence of any plausible etiology) and secondary. As secondary causes of APS, we recognize auto- 
immune diseases (mostly systemic lupus erythematosus), neoplasia, use of certain medicines, infections and some other clinical situations [6].

\section{CORRELATION BETWEEN ANTIPHOSPHOLIPID ANTIBODIES AND CANCER}

When it comes to cancer, it is well known that this condition, regardless of the type, is associated with a fourfold increase in thrombosis risk. Moreover, if the cancer is treated using chemotherapy, the risk of thrombosis increases even further: six-fold [7]. So, the higher risk is encountered in patients having advanced cancer, while receiving chemotherapy [8]. In addition, thrombosis may be the first manifestation of a malignancy: around $10 \%$ of patients with "idiopathic" thrombosis will be diagnosed as having a form of cancer in the next 5 to 10 years after the initial thrombotic episode [9]. Usually, recurring venous thrombosis in the context of cancer, also known as Trousseau's syndrome, is difficult to treat [6].

The presence of aPL antibodies has been rather extensively reported in association with various solid and hematological cancers; this has led to the hypothesis that aPL might have a pathogenic role in the development of thrombosis in malignancies [10-12]. The mechanism by which aPLs are produced in cancer patients are poorly understood. The relation between cancer and the presence of antinuclear antibodies is known for quite a long time, suggesting the possibility of any other immunological abnormalities [13]. The aPL antibodies may be the consequence of the presence of the cancer or of the specific cancer therapy. Furthermore, since the appearance of cancer immune therapies, which now we know can have quite a stimulating effect on the immune system, one might expect the increase in occurrence of autoantibodies in patients treated with this kind of therapies [14-15]. There are many suggestions as to what are the mechanism underlying the production of aPL antibodies in cancer: 1 . Secretion of aCL antibodies by the tumor cells; 2. Production of monoclonal immunoglobulins with LA and aCL activities; 3 . Production of autoantibodies as a response to some tumor antigens [16]. Six years ago, it has been demonstrated that the aPL-positive IgG from patients with autoimmune disease rapidly accelerates tumor angiogenesis and, thus, tumor progression and extension [17]. It has also been shown that, in the circumstance of cancer, there is an activation of endothelial function with the expression of tissue factor, as well as an ac- tivation of platelets. All of these, disrupt the coagulation and fibrinolysis pathways, leading to the hypercoagulation status associated with neoplasia $[18,19]$. It is noteworthy that, in the presence of aPS, the same mechanisms contribute to the development of thrombosis characteristic of APS [20]. In addition to all of these mechanism, there seem to exist some gentic links between thrombosis development and APS and cancer $[21,22]$. So, probably in the future, studies dedicated to all of these hypothesis may reveal some new insights into the intimate mechanisms of occurrence of thrombosis in aPL positive cancer patients, as well as into some new therapeutic options for treating this potentially life-threatening clinical picture.

\section{MALIGNANCIES AND ANTIPHOSPHOLIPID SYNDROME}

As to the interrelation APS-cancer, there can be, at least theoretically, two ways of looking at it: the presence of aPL antibodies in cancer and the presence of cancer in aPL positive patients.

There are numerous reports and studies pertaining to the occurrence of aPLs in cancer. The prevalence and the incidence of these antibodies variable depending on the study, but nevertheless, their presence should be accounted for in order to be aware of a supplementary thrombotic risk in neoplastic patients. Bazan et al. reported in their study a prevalence of $24 \%$ of aPLs, which was significantly higher than that of controls $(p<0.0001)$. If there were to separate on types of aPL, $5.8 \%$ were LA, $12.14 \%$ were aCL and $5.8 \%$ were of the anti- 32 -GPI type. Interestingly and remarkable is the fact that thrombotic events did not differ significantly in occurrence, between the aPL positive and negative patients, respectively [23]. In concordance with these findings, an Iranian group reported in 156 cancer patients $(67 \%$ with a solid cancer, the rest with a hematological cancer) a prevalence of $21.2 \%$ of aPLs, with no significant difference between the two types of cancer [24]. In 2006, Miesbach et al. reported on 58 patients with solid cancers (77\%) and hematologic cancers (33\%). They found that aCL antibodies were positive in $48 \%$ of solid tumor patients and $62 \%$ of hematologic cancers, while LA was positive in $54 \%$ of the solid tumor patients and $42 \%$ of hematologic cancer patients [25]. In non-Hodgkin's lymphoma, the prevalence of high levels of aPLs is $41 \%$, the most prevalent serotype being the anti- 32 -GPI antibodies (86 patients) [26]. In Romania, Tanaseanu et al. reported in 2001, 
confirmed APS in 18 of 46 patients with cancer, 14 being LA positive and 3 aCL positive [27].

The other side of the aPL-cancer interrelation, is the occurrence of cancer in patients with antiphospholipid antibodies. In this respect, already in 1988, Jude and co-workers, analyzing patients with LA-positive autoimmune diseases, revealed the presence of any form of cancer, in $17 \%$ of them [28]. In another study [29], 6 years later-on, the prevalence of cancer among aPLs patients, was 20\%. Moreover, from another study, with a follow-up period of 4 years, among 360 aPL-positive patients, four developed non-Hodgkin's lymphoma (this incidence being significantly higher than in the general population. The authors postulate that patients presenting APS are at increased risk of developing malignancies [30]. Surprisingly, this finding was confirmed by the the observation that $41.6 \%$ of aPL-positive patients developed a type of solid malignancy [10]. Nine percent of CPAS registry patients, developed cancer, with hematologic cancer (leukemia and lymphoma) being the most prevalent [31]. Between 1998 and 2018, there were 38 case-reports of associated cancer to APS [11]. Since "post hoc, ergo propter hoc" is not always true, it would be very interesting to try and solve this peculiar and somewhat unexpected occurrence of neoplasia in patients displaying laboratory and/or clinical signs of APS. Of course, it may be that those events are just two causally unrelated events,

Conflict of interest: none declared

Financial support: none declared

\section{REFERENCES}

1. Bustamante JG, Goyal A, Bansal P et al. Antiphospholipid syndrome. Treasure Island (FL) StatPearls Publishing 2021.

2. Miyakis S, Lockshin MD, Atsumi T, Branch DW, Brey RL, Cervera R, Derksen RH, DE Groot PG, Koike T, Meroni PL, Reber G, Shoenfeld Y, Tincani A, Vlachoyiannopoulos PG, Krilis SA. International consensus statement on an update of the classification criteria for definite antiphospholipid syndrome (APS). J Thromb Haemost. 2006 Feb;4(2):295-306.

3. Juby AG, Davis P. Prevalence and disease associations of certain autoantibodies in elderly patients. Clin Invest Med. 1998 Feb;21(1):4-11.

4. Duarte-García A, Pham MM, Crowson CS, Amin S, Moder KG, Pruthi RK, Warrington KJ, Matteson EL. The Epidemiology of Antiphospholipid Syndrome: A Population-Based Study. Arthritis Rheumatol. 2019 Sep;71(9):1545-1552.

5. Cervera R, Bucciarelli S, Plasín MA, Gómez-Puerta JA, Plaza J, Pons-Estel G, Shoenfeld Y, Ingelmo M, Espinos G; Catastrophic Antiphospholipid Syndrome (CAPS) Registry Project Group (European Forum On Antiphospholipid Antibodies). Catastrophic antiphospholipid syndrome (CAPS): descriptive analysis of a series of 280 patients from the "CAPS Registry". J Autoimmun. 2009 MayJun;32(3-4):240-5.

6. Tanasescu C. Sindromul antifosfolipidic. Bucuresti: Editura Academiei Romane, 2005.

7. Heit JA, Silverstein MD, Mohr DN, Petterson TM, O'Fallon WM, Melton LJ 3rd. Risk factors for deep vein thrombosis and pulmonary one being just "the innocent bystander" of the other, or the other way around with aPLs really being causative of neoplasia. It is a relation that has not been fully explored or understood and, when it will be so, it might seriously impact the management of APS in context of cancer and vice-versa.

As it has already been described for some time, there is a special type of APS, called the seronegative APS, in which patients have typical clinical manifestation intensely suggestive of APS, but in the persistent absence of aPLs (conventional ones) on multiple occasions [32]. There are some reports of malignancies observed in such patients, namely seronegative APS patients [33,34], but of course it is very difficult to ascertain these occurrences as causative not random, in nature.

\section{CONCLUSIONS}

To conclude, even though aPL positivity may help in predicting risk of thrombosis in cancer patients, there is not enough evidence that determining aPLs should become routine practice in every neoplasia patient. On the other hand, there is quite a body of evidence that cancers are associated with an increased risk of developing aPL antibodies and clinicians caring for neoplastic patients should be aware of this increased risk, which adds on to the "intrinsic" thrombotic risk of such a fragile patient.

embolism: a population-based case-control study. Arch Intern Med 2000 Mar 27;160(6):809-15.

8. Lee AY, Levine MN. The thrombophilic state induced by therapeutic agents in the cancer patient. Semin Thromb Hemost. 1999;25(2):137-45

9. Schulman $S$, Lindmarker $P$. Incidence of cancer after prophylaxis with warfarin against recurrent venous thromboembolism. Duration of Anticoagulation Trial. N Engl J Med. 2000 Jun 29;342(26):19538.

10. Gómez-Puerta JA, Cervera R, Espinosa G, Aguiló S, Bucciarelli S, Ramos-Casals M, Ingelmo M, Asherson RA, Font J. Antiphospholipid antibodies associated with malignancies: clinical and pathological characteristics of 120 patients. Semin Arthritis Rheum. 2006 Apr;35(5):322-32.

11. Islam MA. Antiphospholipid antibodies and antiphospholipid syndrome in cancer: Uninvited guests in troubled times. Semin Cancer Biol. 2020 Aug;64:108-113.

12. Pugliese L, Bernardini I, Pacifico E, Viola-Magni M, Albi E. Antiphospholipid antibodies in patients with cancer. Int $\mathrm{J}$ Immunopathol Pharmacol. 2006 Oct-Dec;19(4):879-88.

13. Zeromski JO, Górny MK, Jarczewska K. Malignancy associated with antinuclear antibodies. Lancet. 1972 Nov 11;2(7785):1035-6.

14. Thiagarajan P, Shapiro SS, De Marco L. Monoclonal immunoglobulin M lambda coagulation inhibitor with phospholipid specificity. Mechanism of a lupus anticoagulant. J Clin Invest. 1980 Sep;66(3):397-405. 
15. Becker JC, Winkler B, Klingert S, Bröcker EB. Antiphospholipid syndrome associated with immunotherapy for patients with melanoma. Cancer. 1994 Mar 15;73(6):1621-4.

16. 16. Zuckerman E, Toubi E, Golan TD, Rosenvald-Zuckerman T, Sabo E, Shmuel Z, Yeshurun D. Increased thromboembolic incidence in anti-cardiolipin-positive patients with malignancy. $\mathrm{Br} \mathrm{J}$ Cancer. 1995 Aug;72(2):447-51.

17. Wu YY, V Nguyen A, Wu XX, Loh M, Vu M, Zou Y, Liu Q, Guo $P$, Wang Y, Montgomery LL, Orlofsky A, Rand JH, Lin EY. Antiphospholipid antibodies promote tissue factor-dependent angiogenic switch and tumor progression. Am J Pathol. 2014 Dec;184(12):3359-75.

18. Lip GY, Chin BS, Blann AD. Cancer and the prothrombotic state. Lancet Oncol. 2002 Jan;3(1):27-34.

19. Gouin-Thibault I, Achkar A, Samama MM. The thrombophilic state in cancer patients. Acta Haematol. 2001;106(1-2):33-42.

20. Schreiber K, Sciascia S, de Groot PG, et al. Antiphospholipid syndrome. Nat Rev Dis Primers. 2018;4:1-20.

21. D'Asti E, Magnus N, Meehan B, Garnier D, Rak J. Genetic basis of thrombosis in cancer. Semin Thromb Hemost. 2014 Apr;40(3):284-95.

22. Islam MA, Khandker SS, Alam F, Kamal MA, Gan SH. Genetic risk factors in thrombotic primary antiphospholipid syndrome: A systematic review with bioinformatic analyses. Autoimmun Rev. 2018 Mar; 17(3):226-243.

23. Bazzan M, Montaruli B, Vaccarino A, Fornari G, Saitta M, Prandoni P. Presence of low titre of antiphospholipid antibodies in cancer patients: a prospective study. Intern Emerg Med. 2009 Dec;4(6):491-5.

24. Mortazavizadeh M, Sadeghmanesh R. Antiphospholipid antibodies in neoplastic patients, Iran J Cancer Prev. 2012;2(2):63-66.

25. Miesbach W, Scharrer I, Asherson R. Thrombotic manifestations of the antiphospholipid syndrome in patients with malignancies. Clin Rheumatol. 2006 Nov;25(6):840-4.
26. Bairey O, Blickstein D, Monselise Y, Lahav J, Stark P, Prokocimer M, Nativ HM, Kirgner I, Pazgal I, Shaklai M. Antiphospholipid antibodies may be a new prognostic parameter in aggressive non-Hodgkin's lymphoma. Eur J Haematol. 2006 May;76(5):38491.

27. Tanaseanu C, Tanaseanu S, Urban A, et al. Paraneoplasic antiphospholipid syndrome-a possible main cause of thrombosis in cancer patients. Ann Rheum Dis. 2001;60(1):101.

28. Jude B, Goudemand J, Dolle I, Caron C, Watel A, Tiry C, Cosson A. Lupus anticoagulant: a clinical and laboratory study of 100 cases. Clin Lab Haematol. 1988;10(1):41-51.

29. Schved JF, Dupuy-Fons C, Biron C, Quére I, Janbon C. A prospective epidemiological study on the occurrence of antiphospholipid antibody: the Montpellier Antiphospholipid (MAP) Study. Haemostasis. 1994 May-Jun;24(3):175-82.

30. Finazzi G. The Italian Registry of Antiphospholipid Antibodies. Haematologica. 1997 Jan-Feb;82(1):101-5.

31. Miesbach W, Asherson RA, Cervera R, Shoenfeld Y, Gomez Puerta J, Bucciarelli S, Espinoza G, Font J; Members of CAPS Registry Group. The catastrophic antiphospholipid (Asherson's) syndrome and malignancies. Autoimmun Rev. 2006 Dec;6(2):947.

32. Islam MA. Antiphospholipid antibodies and antiphospholipid syndrome in cancer: Uninvited guests in troubled times. Semin Cancer Biol. 2020 Aug;64:108-113.

33. Hughes GR, Khamashta MA. Seronegative antiphospholipid syndrome. Ann Rheum Dis. 2003 Dec;62(12):1127.

34. Abdel-Wahab N, Tayar JH, Fa'ak F, et al. Systematic review of observational studies reporting antiphospholipid antibodies in patients with solid tumors. Blood Adv. 2020;4(8):1746-1755. 